\title{
Hereditary Gastric Cancer: Review of Literature
}

\author{
Jelena Pogodina*/**, Genadijs Trofimovics*/**, Edvins Miklasevics*/**, Roberts Ribenieks* \\ *Pauls Stradins Clinical University Hospital, Riga, Latvia \\ **Institute of Oncology, Riga Stradins University, Latvia
}

\begin{abstract}
Summary
Worldwide, gastric cancer is one of the most common forms of cancer, with a high morbidity and mortality. Both environmental and genetic factors have a role in the aetiology of gastric cancer. Familial clustering of gastric cancer is seen in 10-15\% of cases, and approximately $3 \%$ of gastric cancer cases arise in the setting of hereditary diffuse gastric cancer ( HDGC). In families with HDGC, gastric cancer presents at relatively young age. Germline mutations in the $\mathrm{CDH1}$ gene are the major cause of HDGC and are identified in approximately $25-40 \%$ of families which fulfill strict criteria. Prophylactic gastrectomy is the only option to prevent gastric cancer in individuals with a $\mathrm{CDH} 1$ mutation. However, in the majority of families with multiple cases of gastric cancer no germline genetic abnormality can be identified and therefore preventative measures are not available, except for general lifestyle advice. Future research should focus on identifying new genetic predisposing factors for all types of familial gastric cancer.
\end{abstract}

Key words: gastric cancer; hereditary diffuse gastric cancer; $\mathrm{CDH1}$; E-cadherin; prophylactic gastrectomy.

\section{INTRODUCTION}

Gastric cancer (GC) are major health problems in many countries throughout the world. With an estimated 989,000 new cases per year ( $8.0 \%$ of new cancer cases) it is in fourth place behind cancers of the lung, brest, and colon and rectum. Even though the incidence is rapidly declining in the western world, it is still the second most common cause of death from cancer, with 740,000 deaths annually (20). Gastric cancer's incidence shows large geographic differences worldwide. Highrisk areas include East Asia (Japan, China and Korea), Eastern Europe, and parts of Central and South America ( ASR in men, $>40$ per 100,000). Incidence rates are low in North Europe, North America and Australia ( < 15 per 100,000) (20).

In Latvia gastric cancer takes the 4th place among the whole population (3rd place in males and 6th place in females) and the prognosis of advanced gastric cancer remains poor. The age-standardized incidence rate of gastric cancer in Latvia is higher than in European Union (EU) -28.6 cases and 14.6 cases of gastric cancer (per 100 000) were reported in men and women, respectively, in Latvia. The EU age-standardized incidence rate is lower: 18.2 cases and 8.1 cases per 100000 are reported in men and women, respectively. The age standardized mortality rate in Latvia is also at least twice higher than reported in the EU: 27.5 cases and 12.0 cases per 100000 in men and women, respectively, versus 12.2 cases and 5.7 cases per 100000 in men and women, respectively, in the EU (20).

Gastric cancer incidence worldwide is more than double in men than in women ( rate ratio 2.2:1.0). With a mean age at diagnosis above 60 years, gastric cancer is predominantly a disease of the elderly (36). Only 6-7\% of patients with gastric cancer present before the age of 50 , and less than $2 \%$ before age 40 . Gastric cancer is usually diagnosed at an advanced stage, with $>50 \%$ of patients having stage 3 or 4 disease at presentation.
Advanced gastric cancer has a poor prognosis, with a relative 5 - year survival rate of $7-27 \%(10,36)$.

\section{Classification}

Gastric carcinoma is a heterogeneous disease, which is reflected by the diversity of the various histopathological classification schemes (4). The most commonly used are those of the WHO (4) and Laurén (27). The practical scheme of Laurén divides GC roughly into three main types; the diffuse type, the intestinal type and a rest group composed of mixed and indeterminate type (3). The intestinal type is more common in the general population, more likely to be sporadic and related to environmental factors. Intestinal GC shows glandular or tubular components with various degrees of differentiation. The diffuse type is more likely to have a primary genetic etiology, a subset of which, known as hereditary diffuse gastric cancer (HDGC), is due to the E-cadherin ( $\mathrm{CDHl}$ ) germline mutation. Diffuse GC consists of poorly cohesive single cells without gland formation. Often signet ring cells are present; therefore it is also referred to as signet ring cell carcinoma (26). In North America the distribution of the different subtypes is approximately $50 \%$ pure intestinal, $35 \%$ pure diffuse and $15 \%$ mixed diffuse-intestinal (32).

\section{Etiology of gastric cancer}

Gastric cancer is a multifactorial disease, resulting from a combination of environmental factors and genetic alterations. Environmental factors are mainly involved in the etiology of the intestinal type of GC. The main environmental factor involved is Helicobacter pylori $(H$. Pylori) infection, smoking and diet. In young people, in whom carcinomas are more likely to be due to genetic susceptibility, a greater proportion shows the diffuse type, suggesting that especially in this subtype germline genetics play a role (4). Familial aggregation of gastric cancer is known to occur in approximately $10-15 \%$ of 
the patients (26). Epidemiologic studies have shown that in the general population the risk of gastric cancer in first-degree relatives with any type of gastric cancer is increased 2-3 fold (16). As yet, however, in the vast majority of these patients the underlying genetic cause remains unknown. The most important GC susceptibility gene is $C D H 1$, which accounts for $1-3 \%$ of gastric cancers (35). Predisposing $\mathrm{CDHl}$ mutations have been encountered in about $30 \%$ of strictly selected Hereditary Diffuse Gastric Cancer (HDGC) families $(21,31)$. Moreover, $\mathrm{CDH} 1$ germline mutations may also occur in approximately $7 \%$ of patients diagnosed before 50 years of age with tumors exhibiting either a diffuse or a mixed histology (9).

\section{Hereditary diffuse gastric cancer caused by germline $\mathrm{CDH} 1$ mutations}

Hereditary diffuse gastric cancer (HDGC) is defined as a syndrome of inherited predisposition to cancer with an autosomal dominant inheritance pattern.

In 1998, Guilford et al. identified germline mutations in the $C D H 1$ gene as a cause of hereditary diffuse gastric cancer (17). CDHl encodes the protein E-cadherin, which plays an important role in cell-cell adhesion and the maintenance of epithelial integrity (3). The mutation detection rate is approximately $50 \%$ in families with two gastric cancers in first-degree relatives with at least one diffuse gastric cancer (DGC) diagnosed before age 50 , or three or more DGC in close relatives diagnosed at any age (31). The percentage decreases if also single cases of DGC below the age of 35 are included (21). Germline $C D H 1$ mutations are found in all ethnic groups (13).

The most common types of mutation are small insertions or deletions (35\% of the mutations). Missense mutations occur in $28 \%$ of families, nonsense mutations and splice site mutations are both observed in $16 \%$ of families. Large exonic deletions are relatively rare, with a frequency of about $5 \%(5)$.

For both men and women, CDHI mutation carriers have a cumulative risk of gastric carcinoma by 80 years of age of $80 \%$, with a mean age at diagnosis of 40 years. Additionally, women carrying a $\mathrm{CDHl}$ mutation have a $60 \%$ lifetime risk for developing lobular breast cancer (13).

\section{Genetic counseling and criteria for $\mathrm{CDH} 1$ mutation testing}

Genetic counseling is an essential component of the management of HDGC. It includes the analysis of the family history of at least three generations and histopathological confirmation of gastric (pre) malignancies. The revised international criteria as established by the International Gastric Cancer Linkage Consortium (IGCLC) to select patients with an increased risk of familial gastric cancer for $\mathrm{CDH}$ l mutation testing:

1. diffuse gastric cancer case below age 40, or

2. gastric cancer cases in a family, one confirmed diffuse gasrtric cancer below age 50 , or

3. confirmed diffuse gastric cancer cases in 1st or 2nd degree relatives independent of age,or

4. personal or family history of diffuse gastric cancer and lobular breast cancer, with one diagnosis below age 50 .

(13). Genetic testing is preferably initiated in an affected relative. In most countries the youngest age at which relatives at risk should be offered testing is set at age 18. Rare cases of gastric cancer before age 18 have been reported, but the overall risk of DGC before the age of 20 is very low $(1,33)$.

\section{Proposed mechanism of HDGC initiation}

In 2009, Humar and Guilford proposed a mechanism of HDGC initiation (18). E-cadherin is known to play an important role in cell polarity and epithelial tissue architecture $(11,29)$. It is proposed that mutations in $\mathrm{CDHl}$ disturb the cell-cell adhesion mediated by E-cadherin, which causes disruption of the correct spatial organization of the cells. This in turn may interfere with processes that regulate cell division, such as the orientation of the mitotic spindle. Abrogated cell polarity may also lead to the disruption of cell fate determination $(18,23,24)$. These disturbed processes can ultimately result in the displacement of cells with self-renewal capacity into the lamina propria and lead to the formation of signet ring cell carcinomas with the capacity for sustained cell division and thus to progression (19).

\section{Identification of new genes underlying hereditary gastric cancer}

In approximately two thirds of families fulfilling the strict HDGC criteria, no $C D H 1$ mutation is found and they remain genetically unexplained. Most of these families might carry mutations in other, still to be identified, GC susceptibility genes. As binding partner for E-cadherin, mutated $\beta$ - and $\gamma$-catenin have been considered as candidates for diffuse GC predisposition (25). The $\beta$-catenin gene $(C T N N B 1)$ was recently assessed in a series of 40 families with positive history of GC from the Netherlands without finding any mutations (Vogelaar et al., unpublished data, 2012).

Also in families with intestinal type GC exhibiting an autosomal dominant inheritance pattern, genetic susceptibility genes may play a role. No gene has been associated with this type of GC yet. In carefully selected patients next generation sequencing based techniques that allow for exome or even genome wide detection of genetic aberrations, might be exploited to unravel genetic predisposition in an unbiased way.

\section{Prophylactic total gastrectomy in $\mathrm{CDH} 1$ mutation carriers}

Prophylactic gastrectomy is currently the only option to eliminate risk of GC development in $C D H 1$ mutation carriers (30). The prognosis of patients with a prophylactic gastrectomy is very good. The estimated overall mortality for total gastrectomy is $2-4 \%$ with a nearly $100 \%$ risk of long-term morbidity. Associated problems following gastrectomy include abdominal pain after eating, dumping

syndrome, lactose intolerance, fat malabsorption and steatorrhoea and postprandial fullness $(8,13,14,28)$. The optimal timing of prophylactic gastrectomy in 
individuals with CDHImutations is not yet known. Preventive gastrectomy specimens of $\mathrm{CDHl}$ mutation carriers reveal multiple small signet ring cell lesions with low proliferation rates; few of these lesions progress to an aggressive carcinoma beyond the muscular mucosa (2). It is unknown why only some of these lesions develop into aggressive carcinomas. No correlation between patient age and number of small signet ring cell foci has been observed. Blair et al. advise $\mathrm{CDH} 1$ mutation carriers with normal gastric biopsies to consider gastrectomy once the individuals are older than 20 years of age (1). Other authors recommend considering preventive gastrectomy when the $C D H 1$ mutation carrier is 5 years younger than the youngest family member with DGC, which generally means that preventive gastrectomy is postponed to an age later than 18 years (6).

In case of a preventive gastrectomy, total gastrectomy with Roux-en-Y reconstruction is recommended. There is no need for a radical lymph node dissection in the prophylactic setting since mucosal adenocarcinomas without submucosal invasion have a low risk of lymph node metastases (34).

\section{Surveillance endoscopy}

The 'Cambridge surveillance protocol' is advised for $\mathrm{CDH} 1$ mutation carriers who do not want to undergo a prophylactic gastrectomy, to individuals at $50 \%$ risk of being carrier who are not willing to be tested for the mutation as well as for members from HDGC families without a known $\mathrm{CDHl}$ mutation (22). This protocol comprises H.Pylori-testing, annual gastroscopy with 'high definition' endoscope, careful inspection of mucosa during 30 minutes, insufflation and desufflation of the stomach, biopsies of mucosal abnormalities and 30 random biopsies from different gastric regions (antrum, angulus, corpus, fundus, cardia) (13). The endoscopy should be performed using a white light high definition endoscope in a dedicated session with at least 30 minutes allocated to allow for a careful inspection of the mucosa on inflation and deflation, and to allow time for multiple biopsies to be taken (13).

Use of mucolytics such as acetylcysteine may be helpful to obtain good views. Endoscopy permits direct inspection and biopsy of suspicious areas, but diffuse GC is difficult to detect at an early and treatable stage since the lesions tend to spread into the lamina propria without visible exophytic masses. The major problems include difficulties to identify (sub)mucosal lesions and biases in sampling in macroscopically normal-appearing gastric mucosa (15). Such specimens therefore need to be evaluated by pathologists with expertise with this type of lesions. Several studies have shown that even though CDH1 mutation carriers had negative biopsies prior to prophylactic gastrectomy, foci were detected in their gastrectomy specimens $(2,7,19,30)$. Other techniques, such as chromoendoscopic techniques, trimodal imaging, confocal endomicroscopy and molecular imaging techniques are currently not recommended, but need to be further explored in a research setting (13).

\section{CONCLUSIONS}

The overall incidence of GC is declining, which is most likely due to the reduction in environmental risk factors. A positive family history is a strong and consistently reported risk factor for gastric cancer. Germline mutations in the $\mathrm{CDHl}$ gene have been identified as an important cause of HDGC, but still in more than two thirds of strictly selected HDGC families the genetic cause remains unknown. Elucidation of novel gastric cancer susceptibility genes will be an important step towards additional options for gastric cancer prevention. Therefore, identifying new genetic gastric cancer predisposing factors is one of the important targets in the near future.

\section{Conflict of interest: None}

\section{REFERENCES}

1. Barber ME, Save V, Carneiro F, Dwerryhouse S, Lao-Sirieix P, Hardwick RH, Caldas C, Fitzgerald RC: Histopathological and molecular analysis of gastrectomy specimens from hereditary diffuse gastric cancer patients has implications for endoscopic surveillance of individuals at risk. // J Pathol 2008; 216:286-294.

2. Berx G, Becker KF, Hofler H, van RF: Mutations of the human E-cadherin ( $\mathrm{CDH} 1)$ gene. Hum Mutat // 1998; 12:226-237.

3. Blair V, Martin I, Shaw D, Winship I, Kerr D, Arnold J, Harawira P, McLeod M, Parry S, Charlton A, et al.: Hereditary diffuse gastric cancer: diagnosis and management. Clin Gastroenterol Hepatol // 2006; 4:262-275.

4. Bosman FT, Carneiro F, Hruban RH, Theise ND: WHO Classification of Tumours of the Digestive System. 4th edition. Lyon, France: IARC; 2010.

5. Carneiro F, Oliveira C, Suriano G, Seruca R: Molecular pathology of familial gastric cancer, with an emphasis on hereditary diffuse gastric cancer. $\mathrm{J}$ Clin Pathol // 2008; 61:25-30.

6. Charlton A, Blair V, Shaw D, Parry S, Guilford P, Martin IG: Hereditary diffuse gastric cancer: predominance of multiple foci of signet ring cell carcinoma in distal stomach and transitional zone. Gut // 2004; 53:814-820.

7. Chun YS, Lindor NM, Smyrk TC, Petersen BT, Burgart LJ, Guilford PJ, Donohue JH: Germline E-cadherin gene mutations: is prophylactic total gastrectomy indicated? Cancer // 2001; 92:181187.

8. Cisco RM, Ford JM, Norton JA: Hereditary diffuse gastric cancer: implications of genetic testing for screening and prophylactic surgery. Cancer // 2008; 113:1850-1856.

9. Corso G, Pedrazzani C, Pinheiro H, Fernandes E, Marrelli D, Rinnovati A, Pascale V, Seruca R, Oliveira C, Roviello F: E-cadherin genetic screening and clinico-pathologic characteristics of early onset gastric cancer. Eur J Cancer // 201 1; 47:631-639. 
10. Curado MP, Edwards B, Shin HR, Storm H, Ferlay $\mathrm{J}$, Heanue $\mathrm{M}$, Boyle P: Cancer Incidence in Five Continents. IARC Scientific Publication // 2007;

11. Drubin DG, Nelson WJ: Origins of cell polarity. Cell 1996; 84:335-344

12. Ferlay J, Autier P, Boniol M, Heanue M, Colombet M, Boyle P. Estimates of the cancer incidence and mortality in Europe in 2006. Ann Oncol // 2007; 18: $581-92$

13. Fitzgerald RC, Hardwick R, Huntsman D, Carneiro F, Guilford P, Blair V, Chung DC, Norton J, Ragunath $\mathrm{K}$, van Krieken $\mathrm{JH}$, et al.: Hereditary diffuse gastric cancer: updated consensus guidelines for clinical management and directions for future research. J Med Genet // 2010; 47:436-444.

14. Fitzgerald RC, Caldas C: E-cadherin mutations and hereditary gastric cancer: prevention by resection? Dig Dis // 2002; 20:23-31.

15. Fitzgerald RC, Caldas C: Clinical implications of E-cadherin associated hereditary diffuse gastric cancer. Gut // 2004; 53:775-778.

16. Goldgar DE, Easton DF, Cannon-Albright LA, Skolnick MH: Systematic population-based assessment of cancer risk in first-degree relatives of cancer probands. J Natl Cancer Inst // 1994; 86:1600-1608.

17. Guilford P, Hopkins J, Harraway J, McLeod M, McLeod N, Harawira P, Taite H, Scoular R, Miller A, Reeve AE: E-cadherin germline mutations in familial gastric cancer. Nature // 1998; 392:402405.

18. Humar B, Guilford P: Hereditary diffuse gastric cancer: a manifestation of lost cell polarity. Cancer Sci // 2009; 100:1151-1157.

19. Huntsman DG, Carneiro F, Lewis FR, MacLeod PM, Hayashi A, Monaghan KG, Maung R, Seruca R, Jackson CE, Caldas C: Early gastric cancer in young, asymptomatic carriers of germ-line E-cadherin mutations. N Engl J +-

20. Jemal A, Bray F, Center MM, Ferlay J, Ward E, Forman D: Global Cancer Statistics. A Cancer Journal for Clinicians // 201 1; 61: 69-90.

21. Kaurah P, MacMillan A, Boyd N, Senz J, De LA, Chun N, Suriano G, Zaor S, Van ML, Gilpin C, et al.: Founder and recurrent $\mathrm{CDH} 1$ mutations in families with hereditary diffuse gastric cancer. JAMA // 2007; 297:2360-2372.

22. Kluijt I, Sijmons RH, Hoogerbrugge N, Plukker JT, De JD, van Krieken JH, Van HR, Ligtenberg M, Bleiker E, Cats A: Familial gastric cancer: guidelines for diagnosis, treatment and periodic surveillance. Fam Cancer // 2012; 11:363-369.

23. La Vecchia C, Negri E, Franceschi S, Gentile A: Family history and the risk of stomach and colorectal cancer. Cancer // 1992; 70:50-55.

24. Lauren P: The two histological main types of gastric carcinoma: diffuse and so-called intestinaltype carcinoma. An attempt at a histo-clinical classification. Acta Pathol Microbiol Scand // 1965; 64:31-49.
25. Lechler T, Fuchs E: Asymmetric cell divisions promote stratification and differentiation of mammalian skin. Nature // 2005; 437:275-280.

26. Lu B, Roegiers F, Jan LY, Jan YN: Adherens junctions inhibit asymmetric division in the Drosophila epithelium. Nature // 2001; 409:522-525.

27. Lynch HT, Grady W, Suriano G, Huntsman D: Gastric cancer: new genetic developments. J Surg Oncol // 2005; 90:114-133.

28. Miholic J, Meyer HJ, Muller MJ, Weimann A, Pichlmayr R: Nutritional consequences of total gastrectomy: the relationship between mode of reconstruction, postprandial symptoms, and body composition. Surger // 1990; 108:488-494.

29. Nejsum LN, Nelson WJ: A molecular mechanism directly linking E-cadherin adhesion to initiation of epithelial cell surface polarity. J Cell Biol // 2007; 178:323-335.

30. Norton JA, Ham CM, Van DJ, Jeffrey RB, Longacre TA, Huntsman DG, Chun N, Kurian AW, Ford JM: $\mathrm{CDHl}$ truncating mutations in the E-cadherin gene: an indication for total gastrectomy to treat hereditary diffuse gastric cancer. Ann Surg // 2007; 245:873-879.

31. Oliveira C, Senz J, Kaurah P, Pinheiro H, Sanges R, Haegert A, Corso G, Schouten J, Fitzgerald R, Vogelsang $\mathrm{H}$, et al.: Germline $\mathrm{CDHl}$ deletions in hereditary diffuse gastric cancer families. Hum Mol Genet // 2009; 18:1545-1555.

32. Pisani P, Bray F, Parkin DM: Estimates of the worldwide prevalence of cancer for 25 sites in the adult population. Int J Cancer // 2002; 97:72-81 .

33. Pharoah PD, Guilford P, Caldas C: Incidence of gastric cancer and breast cancer in $\mathrm{CDHl}$ (E-cadherin) mutation carriers from hereditary diffuse gastric cancer families. Gastroenterology // 2001; 121:1348-1353.

34. Sano T, Kobori O, Muto T: Lymph node metastasis from early gastric cancer: endoscopic resection of tumour. Br J Surg // 1992, 79:241-244.

35. Stone J, Bevan S, Cunningham D, Hill A, Rahman N, Peto J, Marossy A, Houlston RS: Low frequency of germline E-cadherin mutations in familial and nonfamilial gastric cancer. Br J Cancer // 1999; 79:1935-1937

36. Yamaoka Y, Kato M, Asaka M: Geographic Differences in Gastric Cancer Incidence Can be Explained by Differences between Helicobacter pylori Strains, Inter Med // 2008; 47: 1077-1083.

\section{Address:}

Jelena Pogodina

Pauls Stradins Clinical University Hospital,

Pilsonu street 13, LV - 1002,

Riga, Latvia

E-mail: raisone@inbox.lv 